\title{
Appendix: Pre-Commitment, Cash Transfers, and Timely Arrival for Birth: Evidence from a Randomized Controlled Trial in Nairobi Kenya
}

\author{
By Jessica Cohen, Katherine Lofgren, Margaret McConnell
}

\section{Motivation and Existing Work on Labeled Cash Transfers}

Previous research has demonstrated that labeled cash transfers can encourage specific labeled behaviors and savings goals (Benhassine 2013). Our pre-commitment design relates to a variety of work offering incentives or fines as a means of helping individuals commit to desired behaviors (Bryan 2010) and to the research using active or enhanced active choice to avoid procrastination in decision-making (Carroll 2009; Keller 2011). Because our pre-commitment conditional transfer provides an incentive for earlier and more thorough planning, our design links to research on "implementation intentions" (Milkman 2011). The strong commitment offered in our intervention could worsen delays if it reduces flexibility in responding to unexpected changes in the condition of a women's pregnancy or in supply side factors, a prospect we explore in the paper. A significant body of research has highlighted the potential tradeoff between commitment and flexibility (Amador 2006).

Benhassine, N. et al. 2013. "Turning a Shove into a Nudge? A "Labeled Cash Transfer" for

Education" American Economic Journal: Economic Policy. 2015: 86-125.

Bryan, G, et al. 2010. “Commitment devices” Annual Review of Economics. 2(1):671-698.

Carroll, G, et al. 2009. "Optimal defaults and active decisions" Quarterly Journal of Economics.124: 1639-1676.

Keller, Punam Anand, et al. 2011. "Enhanced Active Choice: A new Method to Motivate Behavior Change” Journal of Consumer Psychology. 21: 376-383.

Milkman, K.L, et al. 2011. "Using implementation intentions prompts to enhance influenza vaccination rates" Proceedings of the National Academy of Sciences. 108: 10415-10420.

Amador, Manuel, et al. 2006. "Commitment vs. Flexibility” Econometrica. 74: 365-396. 


\section{Sampling, Recruitment and Randomization}

The study was conducted between February and September of 2015 in the informal settlements ("slums") of Nairobi, in Kiambu and Nairobi counties. These densely populated areas are within 15 kilometers of the city center and are primarily made up of low-income residential estates shared with industrial enterprises.

Due to budget constraints, recruitment was based on a combination of convenience sampling, snowball sampling and community health worker (CHW) lists of pregnant women. CHWs made lists of pregnant women in the area with contact information. Recruitment events were held in markets and busy intersections in study neighborhoods. Women enrolled were asked if they knew of other pregnant women who could take part in the study. Pregnant women were eligible if they were at 5 through 7 months gestational age, planning to deliver in a facility, not planning on leaving Nairobi during or after pregnancy, were reachable by mobile phone, were 18 or older, and lived in a study neighborhood.

Prior to the baseline survey, women were randomly assigned to a control group or to one of two treatment arms with equal probability. 192 study participants were also randomized to a third arm that received only the first labeled transfer and not the pre-commitment. Because of space constraints for this manuscript we exclude this arm from our analysis. The randomization was stratified on whether this was a woman's first birth, her month of pregnancy, and a geographic identifier grouping contiguous neighborhoods. An independent randomization assigned $25 \%$ of the sample to a short version of the survey that omitted detailed questions about planning (to allow exploration of whether the survey itself changed behaviors).

\section{The Pre-Commitment Transfer Package and Survey Design}

After completing the baseline survey, women in the treatment arm were told about both transfers and that they could "pre-commit" at the next visit. After completing the midline survey, women in the treatment group received the first transfer and were then asked to provide the name of two facilities: one where they planned to deliver and one "Option B" facility, serving as a back-up location in "case of unexpected events, emergencies and complications." A commitment card recording the chosen facilities was left with the respondent. 


\section{Appendix Figure 1: Birth Facility Commitment Card}

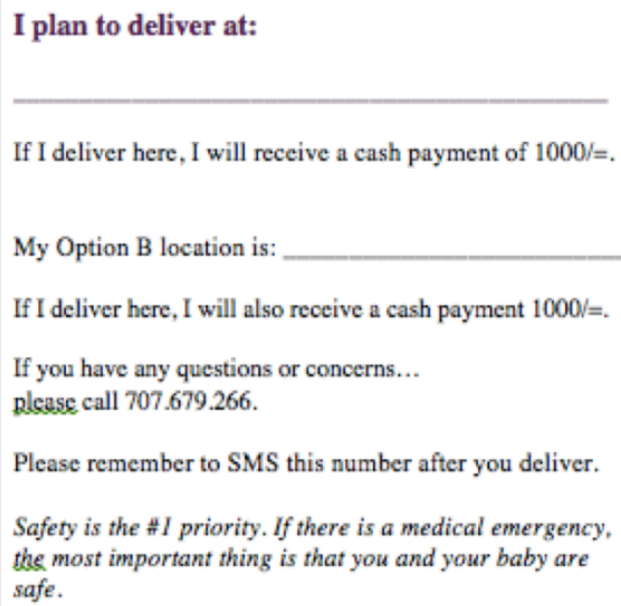

In the baseline and midline surveys women were asked to list all facilities being considered for delivery and then rank them in terms of how likely they were to deliver there and how much they wanted to deliver there if money was no concern on a scale from 1-10 using a visual ladder scale. The endline survey included detailed information about the delivery timeline, from the time of first contractions to the birth of the child, and included detailed information on transportation, delivery experience, and cost. If women had trouble remembering these details, we asked them to provide the name of a labor companion or spouse who might remember this information better. A supplementary survey with a labor companion was conducted for 66 women.

\section{Sample Balance and Attrition}

Appendix Table I shows sample characteristics in the control group and presents p-values for the test of differences between the treatment and control group both for the baseline sample and the endline sample. No significant differences between the treatment and control groups are found at baseline or endline, except that the treatment group is $6 \%$ less likely to be married. Respondents are 25 years old on average with 32\% experiencing their first pregnancy. Almost 90\% are married or partnered and 34\% are employed, with an average household income of $\$ 211$. Over $60 \%$ of respondents report that it would be difficult or very difficult to come up with 
$1000 \mathrm{KSH}$ (the amount of one of the transfers) if someone in their household was sick. The average respondent reported considering 2.8 different maternity facilities at baseline. The sample lives about $13 \mathrm{~km}$ from the national referral hospital in Nairobi.

Appendix Table 1: Characteristics of Study Sample and Balance Across Arms

\begin{tabular}{|c|c|c|c|}
\hline & $\begin{array}{l}\text { Control } \\
\text { Mean }\end{array}$ & $\begin{array}{c}\text { P-value } \\
\text { (Baseline) } \\
\text { H } \\
\text { Control = }\end{array}$ & $\begin{array}{l}\text { P-value } \\
\text { (Endline) } \\
\text { reatment }\end{array}$ \\
\hline Respondent's age (yrs) & 25.66 & 0.40 & 0.24 \\
\hline Married & 0.92 & 0.07 & 0.05 \\
\hline Education (more than primary) & 0.69 & 0.33 & 0.70 \\
\hline First birth & 0.30 & 0.39 & 0.48 \\
\hline Employed at baseline & 0.35 & 0.77 & 0.70 \\
\hline $1000 \mathrm{KSH}$ payment ( $\sim 11 \mathrm{USD})$ is difficult for household & 0.59 & 0.49 & 0.33 \\
\hline Monthly household income ${ }^{a}$ (USD) & 208.97 & 0.87 & 0.84 \\
\hline Number of facilities considered at baseline & 2.78 & 0.67 & 0.87 \\
\hline Distance between neighborhood and national referral hospital & 12.72 & 0.21 & 0.15 \\
\hline
\end{tabular}

The primary reason for attrition was temporary relocation around the time of birth to be with family. Other reasons for attrition were early delivery (before midline), miscarriage, and maternal and neonatal deaths. The neonatal mortality rate in our sample was nearly $5 \%$. In the case of a maternal or neonatal death or miscarriage, no endline was completed.

We also tested for differences in baseline characteristics between women observed at endline and those that were lost to follow-up before the end of the study (Appendix Table 2). Women without endline observations were significantly younger by about 1 year $(\mathrm{p}=0.02)$ and reported about 0.3 fewer birth facilities in their consideration set at baseline $(p=0.04)$. In general, the characteristics of the attritors were consistent with the average characteristics of the women who remained in the study through endline data collection.

\section{Appendix Table 2: Baseline Characteristics of Attritors vs. Those Observed at Endline}




\begin{tabular}{|c|c|c|c|}
\hline & $\begin{array}{l}\text { Mean in } \\
\text { Observed } \\
\text { Women }\end{array}$ & $\begin{array}{c}\text { Mean in } \\
\text { Unobserved } \\
\text { Women }\end{array}$ & $\begin{array}{c}\text { P-value } \\
\mathrm{H}_{0}: \\
\text { Observed = Unobserved }\end{array}$ \\
\hline Respondent's age (yrs) & 25.75 & 24.43 & 0.02 \\
\hline Married & 0.89 & 0.91 & 0.50 \\
\hline Education (more than primary) & 0.67 & 0.66 & 0.87 \\
\hline First birth & 0.31 & 0.38 & 0.25 \\
\hline Employed at baseline & 0.34 & 0.35 & 0.83 \\
\hline $1000 \mathrm{KSH}$ payment ( 11 USD) is difficult for household & 0.61 & 0.62 & 0.88 \\
\hline Monthly household income $^{\mathrm{a}}$ (USD) & 218.99 & 179.65 & 0.18 \\
\hline Number of facilities considered at baseline & 2.87 & 2.58 & 0.04 \\
\hline Distance between neighborhood and national referral & 12.9 & 13.28 & 0.47 \\
\hline \multicolumn{4}{|c|}{ Notes : 80 Observations lost to followup, 281 Observations available at Endline } \\
\hline
\end{tabular}

\section{Timing Measures}

This section provides more detail on the construction and characteristics of the timing index components. We discuss missing values in the timing index and present the correlation between different measures of labor progression to demonstrate that these measures are reliable indicators of true labor progression, rather than simply noise due to respondent recall issues.

Respondents were asked about their dilation at first exam and could report dilation as either number of fingers or centimeters. Number of fingers dilated approximates dilation in centimeters. When women gave both measures $(\mathrm{N}=12)$ we prefer the direct measure of centimeters dilated. A labor companion response was used if no information was available from the woman directly, but this was not the case for anyone in the sample reported in this paper. Of the 234 non-missing responses for contraction spacing at departure, 4 observations used labor companion responses (1.7\%), while 1 out of 227 non-missing responses for contraction spacing at arrival relied on labor companion data (0.4\%). No labor companion responses were used for total time in a facility before birth. In this analysis we have given strict preference to women's responses when available.

For both contraction spacing variables and time in facility, topcoding to the $90^{\text {th }}$ percentile was applied. Contraction spacing for both departure and arrival was topcoded to 30 minutes while time in facility before birth was topcoded to 30 hours. We used topcoding so that the impact measures would not be biased by large outliers.

The percent missing from each of the index components is presented in Appendix Table 3 and varied from a low of $3.8 \%$ for reported time in a facility before birth to the highest percent 
missingness, $37.6 \%$, for dilation at first exam. There was no significant difference in missingness between the treatment and control arms of the study.

Appendix Table 3: Missingness of Timing Variables

\begin{tabular}{|c|c|c|}
\hline & $\begin{array}{l}\text { Control Percent } \\
\text { Missing }\end{array}$ & $\begin{array}{c}\text { P-value } \\
\mathrm{H}_{0}: \\
\text { Control = Treatment }\end{array}$ \\
\hline Contraction spacing at departure for facility ${ }^{\mathrm{a}}$ (min) & 18.0 & 0.58 \\
\hline Contraction spacing at arrival to facility (min) & 21.8 & 0.30 \\
\hline Dilation at first exam $(\mathrm{cm})$ & 37.6 & 0.13 \\
\hline Time in facility before birth (hrs) & 3.8 & 0.86 \\
\hline $\begin{array}{l}\text { Notes : }{ }^{\mathrm{a}} \text { Contraction at departure topcoded to } 90 \text { th percentile } \\
\left.{ }^{\mathrm{b}} \text { Contraction at arrival topcoded to } 90 \text { th percentile ( } 30 \mathrm{mins}\right) \\
{ }^{\mathrm{c}} \text { Time in facility before birth topcoded to } 90 \text { th percentile ( } 30 \mathrm{~h}\end{array}$ & $\begin{array}{l}(30 \text { mins }) \\
\text { hrs })\end{array}$ & \\
\hline
\end{tabular}

Appendix Figure 2 shows the relationship between dilation at first exam and contraction spacing at departure (Panel A) and arrival (Panel B). As dilation at first exam increases, signaling a woman is farther into labor, the reported spacing between contractions tends to decrease. For every minute decrease between contractions at departure for a facility, dilation at first exam increases on average by 0.04 centimeters $(p=0.015)$. Similarly, for every minute decrease in contraction spacing at arrival, dilation at first exam increases by 0.07 centimeters $(p<0.000)$. Notably, women report heterogeneous timing between contractions at any given dilation measurement, especially with reported dilation below $5 \mathrm{~cm}$, emphasizing the need to incorporate information across multiple measures to capture the overall timing in the birthing process.

\section{Appendix Figure 2: Relationship between Contractions and Dilation}
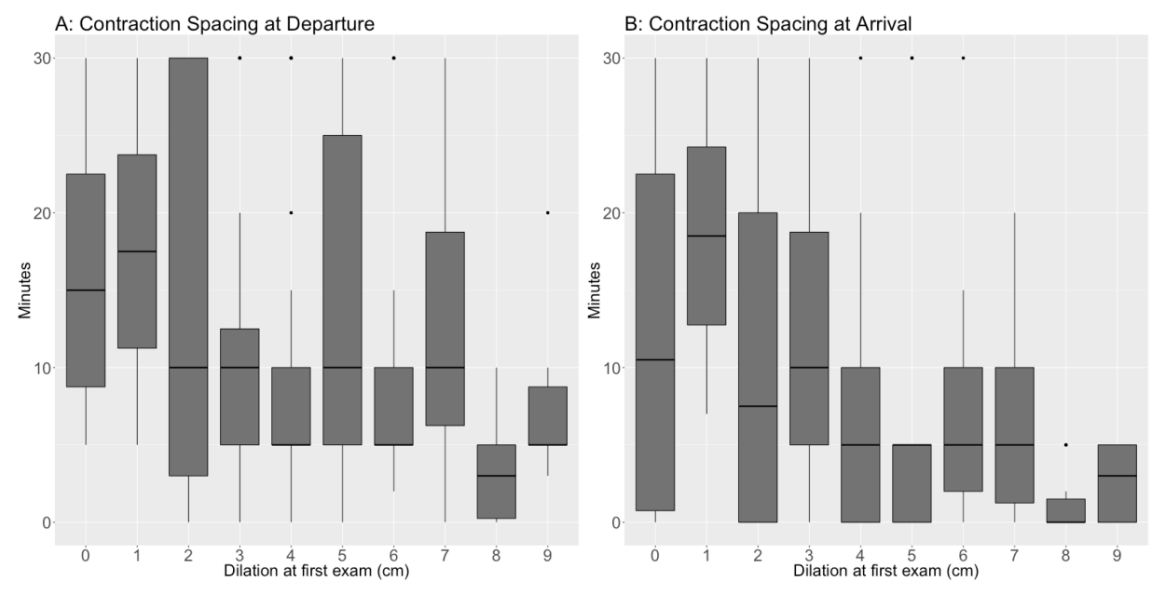


\section{Additional Evidence of Impact on Timing Components}

To explore the impact of the intervention on the distribution of the timing variables, we present kernel density functions for treatment and control for each of the index items in addition to the cumulative density functions included in the main paper as Figures1a-1d. Appendix Figures 3a-3d demonstrate that the intervention shifts the distribution towards earlier arrival for each component of the index, although the shift in dilation is not strong (Figure 3c).

\section{Appendix Figure 3: PDFs of Treatment vs. Control}
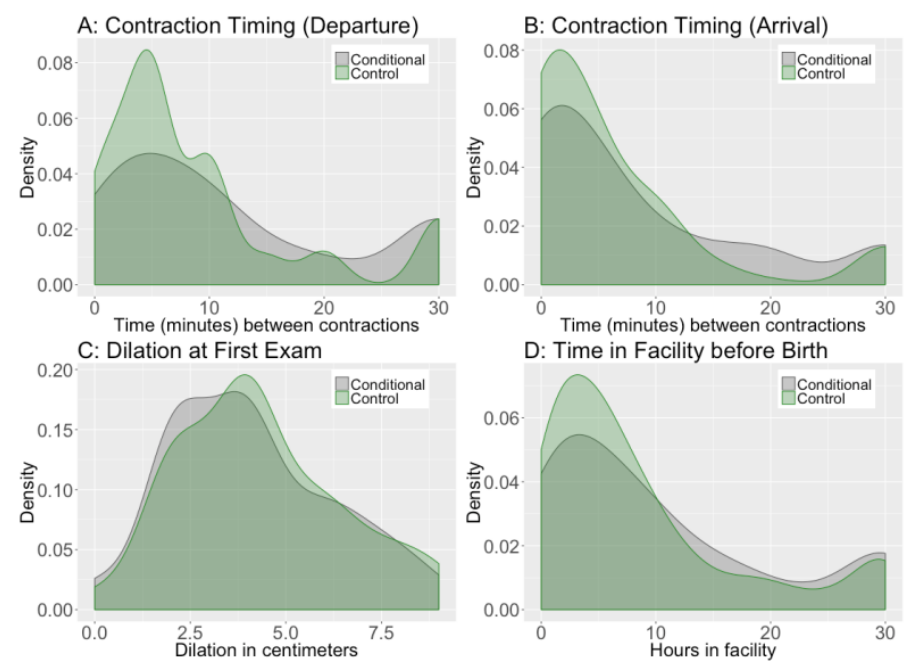

\section{Impact of Intervention on Emergency Referrals and Being Turned Away from a Facility}

In this study a total of 25 percent of women report having been turned away from a facility. Reasons women reported being turned away from a facility include staff strikes, staff or facility capacity constraints, water or electrical shortages, and nighttime arrivals when facilities were closed. 14\% of women report being turned away from a facility either because of a facility issue or because they were not deemed to be far enough in labor. Appendix Table 4 shows that the intervention had no impact on the likelihood of being turned away from a facility for these reasons. 15 percent of the total study sample reports an emergency referral during labor. Appendix Table 4 demonstrates that the intervention had no significant effect on the probability of having an emergency referral. 


\section{Appendix Table 4: Impact of Treatment on Referrals and Being Turned Away}

\begin{tabular}{|c|c|c|}
\hline & $\begin{array}{c}\text { Mean } \\
\text { in } \\
\text { Control }\end{array}$ & $\begin{array}{c}\text { Coefficient on } \\
\text { Treatment } \\
\text { [Standard Error }]\end{array}$ \\
\hline \multicolumn{3}{|l|}{ Turned Away or Referred by a Facility } \\
\hline Turned away due to a facility issue & 0.02 & $\begin{array}{c}0.03 \\
{[0.02]}\end{array}$ \\
\hline Turned away when arrived too early in labor & 0.10 & $\begin{array}{c}0.02 \\
{[0.04]}\end{array}$ \\
\hline Emergency referral & 0.17 & $\begin{array}{c}-0.04 \\
{[0.04]}\end{array}$ \\
\hline \multicolumn{3}{|c|}{$\begin{array}{l}\text { Notes : OLS regressions include controls for stratification variables noted } \\
\text { in text. Distance and Transportation categories restricted to women that } \\
\text { gave birth within } 40 \mathrm{~km} \text { of their neighborhood centroid, a total sample of } \\
265 \text { women compared to the full sample of } 281 \text { women } \\
{ }^{\text {a }} \text { Transportation costs topcoded to 90th percentile ( } 16.4 \text { USD) } \\
\text { b Total costs topcoded to } 90 \text { th percentile ( } 252.5 \text { USD) }\end{array}$} \\
\hline
\end{tabular}

